\title{
Татьяна Мартыненко
}

\section{Robert Hassan. The Condition of Digitality: A Post-Modern Marxism for the Prac- tice of Digital Life. London: University of Westminster Press, 2020. 212 pp. ISBN 978-1-912656-67-7.}

Татьяна Мартыненко, социологический факультет МГУ имени М. В. Ломоносова. Адрес для переписки: МГУ (социологический факультет), Ленинские горы, д. 1. стр. 33, Москва, 119234, Россия. ts.martynenko@gmail.com.

Сегодня в социальных науках трудно найти работу, в которой так или иначе не рассматривалось бы влияние новейших цифровых технологий на современные общества. Публикации в ведущих журналах изобилуют анализом статистических данных о доступе к технологиям, уровне цифровизации и социальных последствиях, которые следуют за распространением «цифры». Эти работы во многом носят прикладной характер. Тем интереснее для современного исследователя новая книга австралийского социолога Роберта Хассана. Работу отличает целый спектр теоретико-методологических вопросов, ответы на которые, по мнению автора, позволят нам лучше понять современность.

Хассан наряду с Мануэлем Кастельсом (Castells 1996) и Яном ван Дейком (Van Dijk 2020) является одним из авторов теории сетевого общества (Hassan 2004). На протяжении многих лет автор занимается вопросами цифровой трансформации, социальных проблем информационного общества, «связанности», цифровой темпоральности и др. Если обобщить содержание работы, автор выносит на обсуждение два основных вопроса: что представляет собой жизнь в пронизанном цифровыми технологиями обществе и может ли марксизм предложить адекватный инструментарий для анализа новой социальной реальности. По поводу первого вопроса стоит заметить, что в социальных науках оптимизм в отношении информационно-коммуникационных технологий довольно быстро исчез. Надежды, возлагаемые многочисленными поколениями на достижения науки и техники, рушились, сталкиваясь с новыми формами социального неравенства, которые возникали наряду с возможностями мгновенного доступа к информации и знаниям. Стремление к новому уровню безопасности обернулось новыми формами контроля, а избавиться от информационной перегрузки оказалось сложнее, чем от физической усталости. В новейших технологиях, искусственном интеллекте и работе алгоритмов Хассан видит бо́льшую угрозу человечеству, чем в современном экологическом кризисе.

Для обсуждения второго вопроса автор предлагает нам мысленно вернуться на тридцать лет назад. 1989 год, мир на распутье: провал социалистической модели и успехи капитализма поставили перед марксизмом новые вопросы о судьбах мира (с. 16-17). В это время выходит одна из значимых книг современности «Состояние постмодерна: исследование истоков культурных изменений» Дэвида Харви (Harvey 1990).

Интерес Хассана к работе Харви связан с рассуждениями последнего о необходимости изучения географических границ капитализма и тех потенциальных 
ограничений в возможностях накопления капитала, которые из этого следуют. Чрезвычайно высоко оценивая эту идею для социальных наук, Хассан подчеркивает, что цифровые технологии радикально изменили капитализм и остались фактически за пределами серьезного анализа со стороны современного марксизма. По мнению автора, после финансового кризиса 2008 года мы все живем в состоянии предвосхищения разрушения глобальной капиталистической системы. Bсе чаще марксисты пытаются выяснить, как и когда закончится капитализм и что придет ему на смену ${ }^{1}$. Автор утверждает, что в настоящее время эти вопросы бессмысленны, поскольку современный марксизм так и не смог, во-первых, осознать специфику современности, связанную с цифровыми технологиями (в том числе понять, как работает капитализм сегодня), а во-вторых, переосмыслить себя в качестве постмодернистского марксизма.

Работа Хассана выстраивается вокруг понятия digitality, которое на русский язык чаще всего переводят как дигитальность (дигитализм). Термин означает жизнь в новой цифровой эпохе. Основу для этого состояния обеспечивают процесс оцифровки данных (то есть перевод из аналоговой в цифровую форму), а также цифровизация, предполагающая все большее вовлечение различных сфер общественной жизни в цифровую среду.

Человек давно привязан к технике: инструменты позволяют человечеству стать видом, весьма искусным в преобразовании окружающей среды, и компенсировать природное несовершенство. В современную эпоху обнаруживается ключевой разрыв между технологиями и человеком, поскольку люди по природе своей по-прежнему являются «аналоговыми», в то время как современные технологии стали «цифровыми». Особенность «аналоговых» инструментов заключается в их соразмерности, соизмеримости с человеком (так, размер молотка обусловлен не столько задачами, перед ним стоящими, сколько размерами человеческой руки) (с. 45). Несомненно, не взаимодействовать с цифровыми инструментами и виртуальным окружением невозможно, но эти взаимодействия, по мнению автора, сложны, поскольку соотнести себя с новым миром человек не может (с. 162).

Одной из тем, которые красной нитью проходят через всю работу, является классическая для марксизма проблема отчуждения, приобретающего в цифровую эпоху новые формы (с. 8). Современный человек живет в виртуальном пространстве, где он все больше производит и потребляет. Это пространство создается цифровыми технологиями, реальный мир по сути служит фоном, на котором разворачивается действие виртуальной реальности. Таким образом, человек все больше отчуждается от окружающей природной среды и отношений с техникой (аналоговыми предметами). Сетевая логика колонизировала нашу жизнь, интегрировав нас в систему социальных сетей. Современная эпоха - это эпоха безотносительности, невозможности соотнести себя с цифровыми технологиями. Мир, в котором мы живем, непонятен большинству из нас. Это эпоха избыточности скорости, контактов, информации.

1 Мы действительно встречаем большое количество подобных публикаций. См., например: Валлерстайн и др. 2015. 
Современный капитализм включает три компонента: сервисный, производственный и платформенный (с. 111). Несмотря на то, что сервисная и производственная системы возникли раньше, чем платформенная, их объединяет цифровая логика и сетевое взаимодействие. Платформенный капитализм сочетает в себе как самые грубые, так и самые изощренные на сегодня формы эксплуатации человека (с. 117), поскольку позволяет коммерциализировать те сферы общественной жизни, в которые раньше не мог проникнуть рынок. В работе рассматриваются два вида платформ - функционирующие по запросу (например, Uber, когда работа появляется, только если есть спрос) и рыночные платформы (работают на постоянной основе, любые сервисы по регулярному оказанию услуг или продаже товаров, например, Amazon), хотя есть и те компании, которые объединяют эти системы (с. 79). Центрами цифрового капитализма и основными бенефициарами современности по-прежнему являются города. Очевидна и неравномерность этого процесса: несколько городов мира, таких как Нью-Йорк, Лондон, Шанхай и другие, становятся ключевыми элементами цифрового мира, или (в терминах Парага Ханны) элементами «связанности» (Dobrinskaya and Vershinina 2018).

Одна из проблем платформенного капитализма заключается в прекариатизированном положении наемных работников. Традиционный тип занятости предполагал регулярное взаимодействие между сотрудниками и возникновение солидарности, социальные гарантии и долгосрочные контракты. В современных условиях все чаще встречается проектная форма работы, временная или удаленная занятость, люди вынуждены регулярно выстраивать собственный бренд, относиться к себе как к проекту и бесконечно конкурировать с другими в борьбе за работу. Тем самым технологические преимущества получают прежде всего корпорации. То, что мы живем в эпоху финансового капитализма, не означает, что трудящиеся и низшие слои могут эффективно использовать возможности финансовой системы, чтобы обеспечить себе стабильный источник дохода.

В настоящее время мы наблюдаем интеграцию компьютерных систем и капитализма: они дополняют друг друга и порождают нечто целое. В этом контексте цифровую культуру составляют три ключевых элемента: коммерциализация, инструментализация (предполагающая прежде всего функционирование алгоритмов) и пространственно-временное сжатие (с. 163). И если вопросам коммерциализации и пространственно-временному сжатию уделялось значительное внимание еще с конца XX века, то инструментализация лишь недавно стала предметом анализа. Именно доступ к алгоритмическим технологиям позволяет получать прибыль из финансовой системы.

Большие данные, составляющие основу для действия алгоритмов, являются результатом многочисленных цифровых следов. В этом контексте Хассан предлагает читателю переосмыслить нашу деятельность: совершенно очевидно, что человек выполняет для корпораций, занимающихся сбором информации и получающих на основе ее обработки прибыль, какую-то «работу». Но фактически у нас нет понятийно-категориального аппарата, который позволил бы зафиксировать эти изменения в процессе производства и потребления (с. 160). Мы постоянно вовлечены в сетевое взаимодействие. В этих условиях киберпространство делает кон- 
цепцию рабочего места архаичной. В любое время суток и в любом месте мы получаем электронную почту и отвечаем на звонки. Пандемия новой коронавирусной инфекции еще раз продемонстрировала ограниченные возможности современного человека по различению времени досуга и рабочего.

Появление технологии Web 2.0 и активное участие пользователей в сетевом взаимодействии породило идею о цифровой демократии, предлагалось рассматривать большие данные как своего рода «мудрость толпы» (с. 166), когда большинство помогает сформировать представление о лучших товарах и услугах при помощи системы отзывов и комментариев. Однако при этом не учитывался тот факт, что алгоритмы, изначально предлагающие вам тот или иной товар/услугу, обладают человеческой предвзятостью, поскольку создаются людьми. Предоставление информации о пользователях позволяет манипулировать ими в еще большей степени.

Одной из проблем, которые обсуждает Хассан в своей книге, является роль социологии в современном обществе. По мнению автора, проект публичной социологии (Майкл Буравой и др.) и представление об особой миссии нашей науки несколько преувеличено по причине масштаба современных социальных трансформаций. Основное, что мы должны и можем сделать, это понять, как в условиях цифровой среды функционируют «демократия», «производство», «потребление», «труд», «коммунизм», останутся ли эти понятия прежними в будущем, или мы не можем вписать их в новый технологический контекст.

Помимо рассмотренных нами вопросов, Хассан уделяет внимание проблеме базиса/надстройки, цифровой культуре, обществу потребления, образу современного ученого-марксиста, формированию идентичности, неолиберальному проекту глобализации и многому другому. Работа изобилует ссылками не только на Харви, но и на широкий круг мыслителей от Георга Зиммеля, Арнольда Гелена и Жака Эллюля до Франкфуртской школы, Шерри Теркл, Славоя Жижека и Раймонда Уильямса. Метафора бриколажа, изящно использованная автором для описания специфики цифровой культуры, во многом характеризует его новое произведение: множество аспектов хотел обсудить со своим читателем Хассан. Таким образом, небольшая по объему книга, логично и последовательно выстроенная, скорее ставит вопросы, чем дает ответы на них. В отношении автора вспоминаются слова платоновского Протагора, обращенные к Сократу: «Ты, Сократ, прекрасно спрашиваешь, а тем, кто хорошо спрашивает, мне и отвечать приятно». Книга побуждает к поиску ответов, а потому рекомендуется широкому кругу исследователей, занимающихся изучением современных обществ в условиях цифровизации.

\section{СПИСОК ЛИТЕРАТУРЫ}

Валлерстайн, Иммануил, Рэндалл Коллинз, Майкл Манн, Георгий Дерлугьян, Крэг Калхун. 2015. Есть ли будущее у капитализма? М.: Изд-во Института Гайдара.

Castells, Manuel. 1996. The Rise of the Network Society. Cambridge, MA: Blackwell Publishers. Dobrinskaya, Daria E., and Inna A. Vershinina. 2018. “New 'Connectography': Networks of Cities in the Global World." Revista Espasios 39(16). https://www.revistaespacios.com/a18v39n16/a18v39n16p07.pdf.

Harvey, David. 1990. The Condition of Postmodernity: An Enquiry into the Origins of Cultural Change. Oxford: Blackwell.

Hassan, Robert. 2004. Media, Politics and the Network Society. Glasgow: Open University Press. Van Dijk, Jan. 2020. The Digital Divide. Cambridge: Polity Press. 